\title{
Cohort effects in the educational attainment of second generation immigrants in Germany: An analysis of census data
}

\author{
Regina T. Riphahn \\ WWZ-University of Basel, Petersgraben 51, CH-4003 Basel Switzerland \\ (Fax: +41-61-267 3351; e-mail: regina.riphahn@unibas.ch)
}

Received: 5 April 2001/Accepted: 31 October 2002

\begin{abstract}
Even though second generation immigrants make up ever increasing population shares in industrialized countries we know little about their social integration and wellbeing. This study focuses on the educational attainment of German born children of immigrants. Their schooling success still lags behind that of natives. This paper investigates school attendance and completed degrees of second generation immigrants and finds that even after controlling for characteristics the educational gap remains large and significant. The available evidence suggests that this group as a whole does not assimilate to native educational standards and instead increasingly falls behind.
\end{abstract}

JEL classification: I21, J24, J61

Key words: Second generation immigrants, educational attainment, assimilation

\section{Introduction}

Although they make up increasing shares of Western European populations, up to now second generation immigrants have not received much attention in economic research. Their role is instead discussed in public debates on issues

This research was completed while the author was guest at the Institute for the Study of Labor (IZA) in Bonn, Germany. I am grateful for IZA's hospitality and particularly for the help of Thomas K. Bauer. I thank the anonymous referees and the editors for very helpful comments. Responsible editors: David Card and Christoph M. Schmidt. 
such as youth unemployment, wage and employment discrimination, or crime. Formal scientific analyses of this population suffer from a scarcity of data, which is reflected in a literature that avoids clear distinctions between first and second generation immigrants. Yet this may produce biased results and begs the issue of looking at second generation immigrants as an increasingly important group.

In a society where formal educational degrees are entry requirements at all levels of the vocational and academic training system as in Germany, key factors for lifetime labor market success are determined early in life. If second generation immigrants as an increasing share of the population pass the educational system being systematically disadvantaged, this may justify the consideration of policy interventions. So far few studies measure this group's educational success and its development over time. ${ }^{1}$ In a recent study for the United States Hirschman (2001, p. 334) concludes “... some foreign-born adolescents (and probably some second-generation national-origin groups) are falling behind educationally." That is the issue which this paper investigates for the case of Germany.

Given the importance of parental input in the child education process one would expect immigrant children to start in the educational system with a disadvantage deriving from their parents' lack of familiarity with the schooling system. Several reasons suggest that the extent of this disadvantage might have declined over time in a country like Germany, which since the 1960s has become accustomed to the presence of guestworker families: First, the school and educational system may have adapted to the needs of the growing shares of immigrant children. Second, ethnic capital theory suggests that the educational attainment of immigrant youth is higher, the more individuals of their ethnicity are around and the better they do in the destination country (Borjas 1992). The number of immigrants in Germany has been rising over the last decades, suggesting overall positive cohort effects. Third, since immigration to Germany was concentrated in the 1960s and 1970s, the later born children of immigrants are likely to have parents who are better assimilated to host country circumstances than parents of earlier born cohorts. Thus, more assimilated parents of recently born children might better be able to guide their offspring during their formative years in Germany. Finally, if German society over time improved its capacity to integrate first generation immigrants in its educational and labor market systems, the second generation may have benefitted as well.

In view of these arguments the questions addressed in this study are first, whether German born children of immigrants achieve degrees as high as their native counterparts. After showing that this is not the case we focus second on whether the gap in educational achievement declines and the two groups' schooling attainments converge over time. The strategy of the paper is to compare the schooling achievement of second generation immigrants to that of natives and to investigate cohort effects in educational attainment differences.

These issues are addressed using data from annual German censuses (Mikrozensus), which have not been applied to this question before. The main advantage of this data is the large number of observations and their representative nature. Two measures of educational attainment are analyzed: First, the level of secondary school currently attended by teenagers, which is explored for cohorts born 1970 through 1980, and second the highest 
educational degree completed by cohorts born between 1956 and 1974 . The analysis of the two different educational outcome measures allows one to test different hypotheses.

The policy relevance of these issues results from several considerations: First, the human capital endowment of a population is a crucial input for individual and aggregate economic success, and therefore deserves attention and monitoring. Second, sufficient education is a precondition for the social integration of foreign workers, which has important consequences not only for economic efficiency but also for social, political, and cultural participation. Third, given the fertility differences between natives and immigrants (Mayer and Riphahn 2000) and demographic projections, the already high population share of second generation immigrants will continue to grow. ${ }^{2}$ If a growing share of the population is poorly educated this endangers the funding of the pay-as-you-go social security system beyond the demographic ageing problem. Fourth, European societies will open up to immigration from the east in the foreseeable future. It is important to learn the lessons from past immigration to improve education and integration policies for the migrants yet to come.

The paper proceeds as follows. Section 2 briefly discusses the data, the German educational system, and recent immigration history. Section 3 then carefully lays out the empirical strategy and describes samples and variables used in the analysis of school attendance and completed degrees. The results are presented in Sect. 4 before Sect. 5 concludes.

\section{Dataset and institutions}

\subsection{The German Mikrozensus}

Historically, German legislation required a population census every decade, and a representative one percent random sample of the population every year in between. The latter surveys are called "Mikrozensus" and have been administered since 1956. The statistical office provides public use files with information on 70 percent random samples of the Mikrozensus data which contain up to half a million observations.

The Mikrozensuses cover demographic issues, and are an important source of labor market information. Whereas the entire questionnaire used to be mandatory, recently respondents were given the choice not to answer a number of questions (Emmerling and Riede 1997). The Mikrozensus uses a rotation scheme, where inhabitants of a given house or flat are reinterviewed for up to four years in sequence, during which time the actual inhabitants of the house or flat may leave or change. Unfortunately the 70 percent public use random sample does not allow the identification of survey households over time.

\subsection{Secondary education in Germany}

Before we can fruitfully discuss the issues involved in defining samples and variables it is important to provide background information on the German system of secondary education. In contrast to many countries it is defined by 
a differentiated track system. Already after four grades of primary education (at about age 10) parents and teachers jointly choose the track that seems appropriate for each pupil. These tracks differ in academic orientation and requirements. The basic school (Hauptschule) graduates individuals after six years of secondary education and is traditionally a preparation for blue collar occupations. The middle school (Realschule) also lasts six years and trains for white collar employment. The highest track (Gymnasium) offers nine years of schooling and a degree (Abitur), which is a precondition for academic studies. Depending on the track, pupils typically finish school aged 16 or $19 .^{3}$

\subsection{Immigration to Germany since 1945}

The West German immigration experience can be divided into several phases (Schmidt and Zimmermann 1992): In the first years after World War II West Germany had to absorb about eight million German refugees from former German territories in the East. In the next phase about 2.6 million individuals migrated from East to West Germany until the construction of the Berlin Wall in 1961. Since the early 1960s through 1973 West Germany recruited workers mostly from Italy, Spain, Greece, Turkey, Portugal, and Yugoslavia, who are referred to as guestworkers. They were predominantly employed in manufacturing and construction, typically in low-skill, bluecollar jobs. By the time the recruitment policy was stopped, the foreign-born population in West Germany had grown from 0.7 in 1961 to 4.1 million in 1973. In the seventies and eighties many guestworkers brought their families to Germany and only few returned to their home countries. Since 1989 immigration patterns have been dominated by inflows of ethnic Germans, asylum seekers, and refugees. The foreign population in West Germany, which does not count ethnic German immigrants, increased from 4.5 million at the end of 1988 to 6.6 million at the end of 1999 with a population share up from $7.3-9.9 \%$. In contrast foreigners make up only about 0.5 percent of the population in East Germany.

\section{Empirical strategy and data description}

\subsection{Overall empirical strategy}

We look at two educational outcome measures to address our research questions: The first describes the type of school currently attended by teenagers. This provides an indicator of the quality of education (see Sect. 2.2). The second measure describes the highest educational degree completed by individuals aged 22 and above.

We look at two educational outcome measures because this allows us to test different hypotheses. On the one hand we want to consider all relevant determinants of school choice including parental background. This is possible only when using the first outcome measure because typically pupils only reside with their parents as long as they are attending school. In the Mikrozensus data this living arrangement is a precondition for being able to measure parental characteristics. On the other hand we can only measure cohort 
effects if our sample covers a sufficiently wide range of birth cohorts. The disadvantage of looking at those attending school (here ages 16 through 19) is that we capture only a limited range of birth cohorts. Given the available survey years 1989 through 1996, only the birth cohorts 1970 through 1980 can be observed attending school. In contrast, completed degrees can be evaluated long after leaving school and thus we can study completed degrees also for those born before 1970, in fact we can go back through 1956. For this group we do not observe parental characteristics because these individuals typically have left their parents' home.

To address the first research question, i.e., whether there is an educational gap for the two populations, we regress the categorical indicator of educational attainment $\left(E A^{*}\right)$ on an indicator of second generation immigrant status (Sec.Gen.). Next we control for characteristics such as age, region of residence, or year of the survey $(X)$ to test whether lower educational attainment among second generation immigrants can be explained by these factors. Then a set of parent characteristics $(P)$ is added and immigrantspecific assimilation and country-of-origin indicators $(I)$ are controlled for. If $i$ indexes individuals and $\varepsilon$ indicates a random disturbance term, the general model is:

$$
E A_{i}^{*}=\alpha+\beta_{0} \text { Sec.Gen. }_{i}+\beta_{1} X_{i}+\beta_{2} P_{i}+\beta_{3} I_{i}+\varepsilon_{i} .
$$

If second generation immigrants lag behind natives in their educational attainment, $\beta_{0}$ yields a significant, negative coefficient estimate. If this difference is due to compositional effects of socio-demographic characteristics, region, or survey year, the effect should disappear once the control variables $(X)$ are introduced. If differential parental characteristics drive the education gap, $\beta_{0}$ should lose significance when parental variables $(P)$ are controlled for. Similarly, if the country-of-origin composition among second generation immigrants explains the $\beta_{0}$ outcome, controlling for immigrant-specific variables $(I)$ including country of origin as well as possibly assimilation measures will affect the $\beta_{0}$ measure of the average group effect. To refine the analysis additional interaction effects are considered:

$$
\begin{aligned}
E A_{i}^{*}= & \alpha+\beta_{0} \text { Sec.Gen }_{\cdot i}+\beta_{1} X_{i}+\beta_{2} P_{i}+\beta_{3} I_{i} \\
& +\gamma_{1}\left(X_{i}^{*} \text { Sec.Gen } . i\right)+\gamma_{2}\left(P_{i}{ }^{*} \text { Sec.Gen } \cdot i\right)+\varepsilon_{i} .
\end{aligned}
$$

The coefficients $\gamma_{1}$ and $\gamma_{2}$ yield whether the correlation of given characteristics $(X$ or $P$ ) with educational attainment differs significantly for natives and second generation immigrants.

Once the correlates of educational attainment are described and investigated we proceed to the second question of interest, i.e., whether there are changes over time in the difference in educational attainment between natives and second generation immigrants. The gap in educational attainment may have declined for the more recent second generation immigrant cohorts if the German educational system improved in integrating this group, if the enhanced educational and labor market integration of the first generation benefitted the next generation as well, or if the rising number of immigrants in Germany over the last decades increased the level 
of support that immigrant pupils receive from their ethnic group. To investigate whether the immigrant disadvantage has indeed declined in the recent past we introduce controls for differential cohort effects between natives and second generation immigrants in the model:

$$
E A_{i}^{*}=\alpha+\beta_{0} \text { Sec.Gen }_{\cdot i}+\delta_{0} \text { Cohort }_{i}+\delta_{1}\left(\text { Cohort }_{i}{ }^{*} \text { Sec.Gen }_{\cdot}\right)+\varepsilon_{i} .
$$

If $\delta_{1}$ is statistically significant then its sign indicates whether immigrants' education converges to or diverges from natives'. If significant differences in developments over cohorts can be detected it is then of interest to examine whether they are robust. This implies first a test of different parameterizations of the cohort effect such as a model with quadratic cohort effects or categorical cohort indicators and their interaction terms, and second controls for additional explanatory variables such as $X, P$, and $I$. Therefore the extended model to be estimated is:

$$
\begin{aligned}
E A_{i}^{*}= & \alpha+\beta_{0} \text { Sec.Gen } ._{i}+\delta_{0} \text { Cohort }_{i}+\delta_{1}\left(\text { Cohort }_{i}{ }^{*} \text { Sec.Gen }_{\cdot i}\right) \\
& +\beta_{1} X_{i}+\beta_{2} P_{i}+\beta_{3} I_{i}+\varepsilon_{i} .{ }^{4}
\end{aligned}
$$

The estimation procedures differ for the two outcome measures and are discussed below.

\subsection{General sampling issues}

The analysis compares the educational attainment for representative samples of natives and second generation immigrants. The data are taken from five pooled Mikrozensus surveys conducted in 1989, 1991, 1993, 1995, and 1996. Since the variable describing current school attendance was not provided in the available 1995 data, our analysis of school attendance relies on the other four surveys. The analysis of completed degrees combines all five survey years.

Individuals were coded as natives if they indicated German citizenship. A weakness of the survey instrument is that it does not allow one to distinguish between persons who have only the German citizenship and those that hold the German citizenship as one out of two or more citizenships. ${ }^{5}$ Those individuals who indicated that they are not German nationals were asked about the year they had entered Germany, with one possible answer "born in Germany." Foreign nationals who checked the latter are coded as second generation immigrants. This measure bears three disadvantages: First, we overlook those immigrants who took on German nationality. However, up through the early 1990 s only very small fractions of immigrants residing in Germany actually naturalized as regulations were highly restrictive. ${ }^{6}$ Thus it is unlikely that selective naturalization biases our estimates. Second, it is possible that those coded as second generation immigrants are already third generation immigrants. Third, the question on year of entry was answered voluntarily. Therefore we miss those who preferred not to answer this question, overall $9.2 \%$ of the non German sample. ${ }^{7}$ Those foreign nationals who did provide a year of entry were coded as first generation immigrants. To keep the sample at a manageable size, a ten percent random sample of the native observations was drawn. 
Table 1. Sample composition and dependent variable: Analysis of current school type

\begin{tabular}{|c|c|c|c|c|c|}
\hline & 1989 & 1991 & 1993 & 1996 & All \\
\hline \multicolumn{6}{|l|}{ Sample: Number of observations } \\
\hline Natives & 1628 & 1928 & 1887 & 2039 & 7482 \\
\hline Age 16 & 351 & 459 & 474 & 568 & 1852 \\
\hline Age 17 & 412 & 503 & 466 & 468 & 1849 \\
\hline Age 18 & 385 & 454 & 477 & 520 & 1836 \\
\hline Age 19 & 480 & 512 & 470 & 483 & 1945 \\
\hline Second generation immigrants & 593 & 862 & 926 & 976 & 3357 \\
\hline Age 16 & 177 & 225 & 242 & 257 & 984 \\
\hline Age 17 & 175 & 262 & 233 & 240 & 1001 \\
\hline Age 18 & 129 & 213 & 244 & 236 & 892 \\
\hline Age 19 & 112 & 162 & 207 & 243 & 809 \\
\hline All & 2221 & 2790 & 2813 & 3015 & 10839 \\
\hline \multicolumn{6}{|c|}{ Dependent variable: Mean share in advanced school by subsample (in percent) } \\
\hline Natives & 31.27 & 21.78 & 23.11 & 26.19 & 25.38 \\
\hline Second generation immigrants & 22.43 & 14.04 & 15.01 & 15.06 & 16.09 \\
\hline All & 28.91 & 19.39 & 20.44 & 22.59 & 22.50 \\
\hline
\end{tabular}

Source: Own calculations based on Mikrozensus surveys 1989, 1991, 1993, and 1996.

\subsection{Data preparation for analysis of current school type}

\subsubsection{Dependent variable, sample, and estimator}

The survey asks whether a respondent is currently in school or training, and if so in what kind. Possible answers are kindergarten, primary school, school grades 5-10, advanced school grades 11-13, vocational, and academic training. The question does not allow one to distinguish the type of school that pupils attend up to grade ten. However, for individuals age 16 and above we can determine whether they attend an advanced school (Gymnasium) or pursue other avenues. Since the advanced school degree (Abitur) is a precondition for university studies and is ranked highest among secondary school degrees, it is meaningful to investigate the determinants of advanced school enrollment. The dependent variable describes whether or not an individual is enrolled in an advanced school.

The sample consists of those 10,839 individuals aged 16 through 19, who might participate in advanced schooling. ${ }^{8,9}$ Table 1 first describes the sample composition by group, age, and survey year, and then shows the enrollment rates in advanced school (Gymnasium) for the two subsamples. With an average Gymnasium enrollment rate of $25.38 \%$ among natives and $16.09 \%$ among second generation immigrants the latter seem to lag behind in their educational attainment already during school age. Given that the outcome measure is bivariate, a probit estimator is applied to the pooled cross-sectional data.

\subsubsection{Independent variables}

Unfortunately the available information on individual characteristics is rather limited in the Mikrozensus data. As socio-demographic control variables we 
consider a person's year of birth, sex, whether living in East Germany (relevant after 1989), and the size of the city of residence. Since this measure is not available in the 1996 survey, indicators are coded zero for that year. To control for overall regional and survey year differences we consider vectors of the state of residence and survey year fixed effects. Further explanatory variables are chosen based on theoretical models explaining individual schooling outcomes. Three theoretical approaches can be distinguished in the literature: The child quantity vs. child quality model as developed by Becker (1981), the ethnic capital model as presented by Borjas (1992, 1994), and the investible funds schooling model, which Chiswick (1988) explains. These models suggest that parent characteristics, assimilation, and ethnicity are key determinants of educational attainment.

Since the surveys gather household information, parent information can be matched using the characteristics of the heads of households and their partners. This information is available for about $95 \%$ of all cases. For those youth, who are already heads of households or partners of household heads the indicator "independent" was coded and parent variables were set to zero as such information was not available. For the majority of the sample we have detailed information on parental school attainment and vocational training. ${ }^{10}$ As an indicator of household level assimilation we use years since parents' migration. When this information is not available, the variable is coded zero and an indicator for missing values is introduced instead. ${ }^{11}$ Finally we control for country of origin indicators to measure ethnicity effects.

The independent variables are described in Table 2 separately for natives and second generation immigrants. Two general differences are notable between the samples. One concerns the region of residence: The share of immigrants living in East Germany is much below that of natives reflecting the overall small number of foreigners residing there. Also, in comparison to natives immigrants seem to live more frequently in bigger cities. The second important distinction lies in the subsamples' average parental education. A simple comparison of the shares' of highly educated parents yields that natives generally have much better educated parents. ${ }^{12}$ The multivariate analysis tests whether differences in characteristics explain the gap in educational attainment between natives and immigrants observed in Table 1 . The results of the probit estimations are discussed in Sect. 4.1 below.

\subsection{Data preparation for analysis of completed degrees}

\subsubsection{Dependent variable, sample, and estimator}

The second measure of educational attainment describes individuals' highest completed degree of schooling. The degrees are categorized in three levels: A low degree is coded if individuals completed no degree or the basic school (Hauptschule) degree. The medium category is reserved for those who graduated from either middle school (Realschule), its east German equivalent (Polytechnische Schule), or achieved the Fachhochschulreife, a degree granted to those who partially completed the highest track. ${ }^{13}$ The advanced degree is coded for those who completed the "Abitur" degree at the advanced school (Gymnasium). Those observations for which the degree indicator was missing, were dropped from the sample. ${ }^{14}$ 
Table 2. Explanatory variables: Analysis of current school type

\begin{tabular}{|c|c|c|c|c|}
\hline \multirow[t]{2}{*}{ Variable description } & \multicolumn{2}{|l|}{ Natives } & \multicolumn{2}{|c|}{ Second generation } \\
\hline & Mean & S.D. & Mean & S.D. \\
\hline \multicolumn{5}{|l|}{ Dependent variable } \\
\hline Currently attending advanced school & 0.254 & 0.435 & 0.161 & 0.367 \\
\hline \multicolumn{5}{|l|}{ Demographic variables } \\
\hline Cohort: year of birth -1900 & 74.91 & 2.862 & 75.24 & 2.690 \\
\hline Male sex & 0.403 & 0.491 & 0.404 & 0.491 \\
\hline Lives in East Germany & 0.213 & 0.409 & 0.059 & 0.236 \\
\hline Lives in small city: $<20000$ inhabitants & 0.353 & 0.478 & 0.168 & 0.374 \\
\hline Lives in big city: $>500000$ inhabitants & 0.09 & 0.286 & 0.201 & 0.401 \\
\hline \multicolumn{5}{|l|}{ Survey year indicator } \\
\hline Survey year is 1989 & 0.218 & 0.413 & 0.177 & 0.381 \\
\hline Survey year is 1991 & 0.258 & 0.437 & 0.257 & 0.437 \\
\hline Survey year is 1993 & 0.252 & 0.434 & 0.276 & 0.447 \\
\hline Survey year is 1996 & 0.273 & 0.445 & 0.291 & 0.454 \\
\hline \multicolumn{5}{|l|}{ Parent variables } \\
\hline $\begin{array}{l}\text { Lives independently, i.e., not in parent } \\
\text { household }\end{array}$ & 0.055 & 0.228 & 0.043 & 0.203 \\
\hline Father no schooling/information missing & 0.225 & 0.418 & 0.324 & 0.468 \\
\hline Father lowest schooling degree & 0.435 & 0.496 & 0.581 & 0.494 \\
\hline Father higher schooling degree & 0.340 & 0.474 & 0.095 & 0.294 \\
\hline Father vocational information missing & 0.227 & 0.419 & 0.166 & 0.372 \\
\hline Father no vocational training & 0.086 & 0.281 & 0.502 & 0.500 \\
\hline Father basic vocational training & 0.436 & 0.496 & 0.292 & 0.455 \\
\hline Father advanced vocational training & 0.251 & 0.434 & 0.041 & 0.197 \\
\hline Mother no schooling/information missing & 0.135 & 0.342 & 0.366 & 0.482 \\
\hline Mother lowest schooling degree & 0.487 & 0.500 & 0.556 & 0.497 \\
\hline Mother higher schooling degree & 0.378 & 0.485 & 0.078 & 0.268 \\
\hline Mother vocational information missing & 0.142 & 0.349 & 0.132 & 0.339 \\
\hline Mother no vocat. training & 0.230 & 0.421 & 0.720 & 0.449 \\
\hline Mother basic vocational training & 0.492 & 0.500 & 0.128 & 0.335 \\
\hline Mother advanced vocational training & 0.137 & 0.344 & 0.019 & 0.138 \\
\hline \multicolumn{5}{|l|}{ Parent assimilation variables } \\
\hline Father years since migration & 0.183 & 2.179 & 20.009 & 9.189 \\
\hline Father years since migration missing & 0.937 & 0.243 & 0.101 & 0.302 \\
\hline Mother years since migration & 0.188 & 2.087 & 19.242 & 7.918 \\
\hline Mother years since migration missing & 0.936 & 0.244 & 0.069 & 0.254 \\
\hline \multicolumn{5}{|l|}{ Country of origin indicators } \\
\hline Citizen of Turkey & - & - & 0.492 & 0.500 \\
\hline Citizen of former Yugoslavia & - & - & 0.179 & 0.383 \\
\hline Citizen of Italy & - & - & 0.110 & 0.313 \\
\hline Citizen of Greece & - & - & 0.089 & 0.284 \\
\hline Citizen of other countries & - & - & 0.052 & 0.221 \\
\hline Citizen of Spain & - & - & 0.033 & 0.179 \\
\hline Citizen of Portugal & - & - & 0.015 & 0.124 \\
\hline Citizen of Austria & - & - & 0.012 & 0.110 \\
\hline Citizen of the Netherlands & - & - & 0.006 & 0.079 \\
\hline Citizen of France & - & - & 0.006 & 0.077 \\
\hline Citizen of Great Britain & - & - & 0.004 & 0.064 \\
\hline Citizen of Poland & - & - & 0.001 & 0.039 \\
\hline
\end{tabular}

Source: Own calculations based on Mikrozensus surveys 1989, 1991, 1993, and 1996. 
Table 3. Sample composition: Analysis of completed degrees

\begin{tabular}{lrrrrrr}
\hline Group & 1989 & \multicolumn{1}{c}{1991} & \multicolumn{1}{c}{1993} & \multicolumn{1}{c}{1995} & 1996 & Total \\
\hline Natives & 7038 & 9875 & 10788 & 12006 & 12644 & 52351 \\
Second generation immigrants & 294 & 466 & 739 & 902 & 1026 & 3427 \\
\hline Total & 7332 & 10341 & 11527 & 12908 & 13670 & 55778 \\
\hline
\end{tabular}

Source: Own calculations based on Mikrozensus surveys 1989, 1991, 1993, 1995, and 1996.

Table 4. Dependent variable by subsample: Analysis of completed degrees

\begin{tabular}{lllll}
\hline Degree & Natives & $\begin{array}{l}\text { Second generation } \\
\text { immigrants }\end{array}$ & All & $\begin{array}{l}\text { Number of } \\
\text { observations }\end{array}$ \\
\hline Low & 33.50 & 55.88 & 34.87 & 19452 \\
Medium & 43.50 & 25.50 & 42.39 & 23646 \\
High & 23.00 & 18.62 & 22.73 & 12680 \\
\hline Total & 100 & 100 & 100 & 55778 \\
\hline
\end{tabular}

Source: Own calculations based on Mikrozensus surveys 1989, 1991, 1993, 1995, and 1996.

For the analysis of completed degrees it is important how old individuals are at the time of the survey, because the fraction of those with uncompleted degrees increases for the younger ones. Even though the typical age to complete basic and middle school is 16 and that of leaving the highest track is 19 , we conservatively consider only those who were at least 22 years of age at the time of the survey, to reduce the number of cases with not yet completed degrees. ${ }^{15}$ Since we are interested in the education of recent cohorts, and because the number of second generation immigrants per birth year declines as we go back in time, we consider only individuals born after 1955 . The last observed cohort is born in 1974, 22 years prior to the 1996 survey. Our sample consists of 52,351 natives and 3,427 second generation immigrants, and is described by survey year in Table 3 .

Table 4 presents the distribution of the dependent variable, across sample groups. The figures show clear differences between the samples: The share of native individuals holding advanced degrees exceeds that of second generation immigrants, who have a much higher chance of ending up with low or no degrees. So Table 4 already answers the question whether second generation immigrants keep up with the schooling attainment of natives, they do not.

The second question then asks whether there is a cohort trend in this attainment gap. Does the schooling success of the children of immigrants show signs of convergence to that of natives? A first step to answering this question is the description of schooling developments over time, i.e., across birth cohorts. Figure 1 presents the share of natives and second generation immigrants completing advanced, and low degrees across cohorts. These figures show no signs of convergence. While the share of natives with low degrees has been steadily declining, that of second generation immigrant cohorts went up, and vice versa for advanced schooling degrees suggesting increasing divergence. The multivariate analysis tests whether these developments are statistically significant, and whether they can be explained by 




Fig. 1(a). Cohort shares with low or no completed educational degree



Fig. 1(b). Cohort shares with advanced educational degree (Abitur). Source: Own calculations based on Mikrozensus 1989, 1991, 1993, 1995, and 1996. Note: To reduce fluctuations due to the small number of second generation immigrants for some cohorts, three year moving averages are presented for this group

composition effects captured by controls for covariates. Since the highest completed degree is an ordered discrete dependent variable, an ordered probit estimator is applied for the multivariate analysis.

\subsubsection{Independent variables}

In order to investigate the difference in the educational attainment for natives and second generation immigrants, completed degrees are first regressed on a 
set of explanatory variables. Here the main limitation of the Mikrozensus becomes relevant, its restrictive set of variables. We can control for demographics, measures of assimilation, and vectors of regional, survey year, and country of origin fixed effects.

The demographic variables control for the same set of indicators as described in Sect. 3.3.2, i.e., sex, whether the individual lives in East Germany (relevant after 1989), and the size of the city of residence (not measured in 1996). The only immigrant assimilation indicators available here are whether the person has a partner or children in the home country. These variables were not applied in the analysis of current school attendance above since for teenagers they do not seem to be relevant. The most important omission among the explanatory variables concerns the parent indicators, which are not observed in the data. Table 5 describes the explanatory variables separately for the two subsamples. A comparison across the two groups confirms that the share of individuals living in East Germany is much larger among natives than among second generation immigrants and that the latter tend to live in larger cities. Also the investigated immigrants are on average born about four years after the natives. Calculating the actual age distribution, we obtain for natives an average age of 29.8 and for second generation immigrants of 26.2 years. The relevance of these covariates for educational attainment is investigated using ordered probit estimations. The results are described in Sect. 4.2 below.

In a second analysis step we investigate whether cohort effects play a role in the development of the educational attainment gap between natives and second generation immigrants. To test this possibility various parameterizations of cohort effects are considered in the estimations. The age distribution of the two samples is described by the birth year indicators presented in Table 5. They confirm that while the native sample is more evenly spread over the range of birth years from 1956 through the mid 1970s only few second generation immigrants were born before 1962, which is a result of the overall migration patterns discussed in Sect. 2.3. The results of the estimations are discussed in Sect. 4.3 below.

\section{Discussion of results}

\subsection{Analysis of current school type}

Table 1 yielded that the share of natives attending advanced school exceeds that of second generation immigrants by about one third. If this gap narrows when controlling for the observable characteristics, the education gap is at least in part a result of the subsamples' compositions. The probit estimations presented in Table 6 test this hypothesis.

First we regress the outcome on an indicator of second generation immigrant status, and sets of regional and survey year fixed effect indicators. The latter are highly significant. Model 1 confirms that the average second generation immigrant has a significantly lower probability of attending advanced school than a native. ${ }^{16}$ After controlling for fixed effects the difference in predicted probabilities between the subsamples amounts to about 10 percentage points. A first extension considers demographic characteristics: Older birth cohorts, males, East Germans, and residents of small cities have significantly lower probabilities of attending advanced schools. The 
Table 5. Explanatory variables: Analysis of completed degrees

\begin{tabular}{|c|c|c|c|c|}
\hline \multirow[t]{2}{*}{ Variable description } & \multicolumn{2}{|l|}{ Natives } & \multicolumn{2}{|c|}{ Second generation } \\
\hline & Mean & S.D. & Mean & S.D. \\
\hline \multicolumn{5}{|l|}{ Dependent variable } \\
\hline $\begin{array}{l}\text { Level of completed degree }(1=\text { low, } \\
2=\text { medium, } 3=\text { high })\end{array}$ & 1.895 & 0.744 & 1.627 & 0.779 \\
\hline \multicolumn{5}{|l|}{ Cohort indicators } \\
\hline Cohort: year of birth -1900 & 63.43 & 4.662 & 67.60 & 4.446 \\
\hline Cohort $^{2}:$ cohort $*$ cohort 100 & 40.44 & 5.962 & 45.89 & 5.894 \\
\hline Born 1956-1958 & 0.183 & 0.387 & 0.041 & 0.199 \\
\hline Born 1959-1961 & 0.197 & 0.398 & 0.069 & 0.253 \\
\hline Born 1962-1964 & 0.206 & 0.404 & 0.121 & 0.326 \\
\hline Born 1965-1967 & 0.200 & 0.400 & 0.214 & 0.411 \\
\hline Born $1968-1970$ & 0.135 & 0.342 & 0.231 & 0.422 \\
\hline Born 1971-1973 & 0.070 & 0.256 & 0.273 & 0.445 \\
\hline Born 1974 & 0.009 & 0.095 & 0.050 & 0.219 \\
\hline \multicolumn{5}{|l|}{ Demographic variables } \\
\hline Male sex & 0.503 & 0.500 & 0.558 & 0.497 \\
\hline Lives in East Germany & 0.205 & 0.404 & 0.029 & 0.169 \\
\hline Lives in small city: $<20000$ inhabitants & 0.321 & 0.467 & 0.156 & 0.363 \\
\hline Lives in big city: $>500000$ inhabitants & 0.117 & 0.322 & 0.171 & 0.377 \\
\hline \multicolumn{5}{|l|}{ Assimilation measures } \\
\hline Partner in home country & 0.000 & 0.000 & 0.007 & 0.083 \\
\hline Children in home country & 0.000 & 0.000 & 0.005 & 0.068 \\
\hline \multicolumn{5}{|l|}{ Survey year indicator } \\
\hline Survey year is 1989 & 0.134 & 0.341 & 0.086 & 0.280 \\
\hline Survey year is 1991 & 0.189 & 0.391 & 0.136 & 0.343 \\
\hline Survey year is 1993 & 0.206 & 0.404 & 0.216 & 0.411 \\
\hline Survey year is 1995 & 0.229 & 0.420 & 0.263 & 0.440 \\
\hline Survey year is 1996 & 0.242 & 0.428 & 0.299 & 0.458 \\
\hline \multicolumn{5}{|l|}{ Country of origin indicators } \\
\hline Citizen of Turkey & - & - & 0.299 & 0.458 \\
\hline Citizen of former Yugoslavia & - & - & 0.102 & 0.302 \\
\hline Citizen of Italy & - & - & 0.185 & 0.388 \\
\hline Citizen of Greece & - & - & 0.118 & 0.323 \\
\hline Citizen of other countries & - & - & 0.079 & 0.269 \\
\hline Citizen of Spain & - & - & 0.057 & 0.232 \\
\hline Citizen of Portugal & - & - & 0.011 & 0.106 \\
\hline Citizen of Austria & - & - & 0.050 & 0.219 \\
\hline Citizen of the Netherlands & - & - & 0.064 & 0.245 \\
\hline Citizen of France & - & - & 0.014 & 0.119 \\
\hline Citizen of Great Britain & - & - & 0.012 & 0.109 \\
\hline Citizen of Poland & - & - & 0.008 & 0.090 \\
\hline Number of observations & \multicolumn{2}{|c|}{52351} & \multicolumn{2}{|c|}{3427} \\
\hline
\end{tabular}

Source: Own calculations based on Mikrozensus surveys 1989, 1991, 1993, 1995, and 1996.

coefficient of the second generation indicator remains significant and almost unchanged. It yields a predicted conditional difference between the two subsamples' probability of advanced school enrollment of 11 percentage points. Thus demographics are unlikely to determine the observed gap in advanced school enrollment rates.

Model 3 adds immigrant specific variables such as parental assimilation indicators and replaces the second generation immigrant indicator by the full 


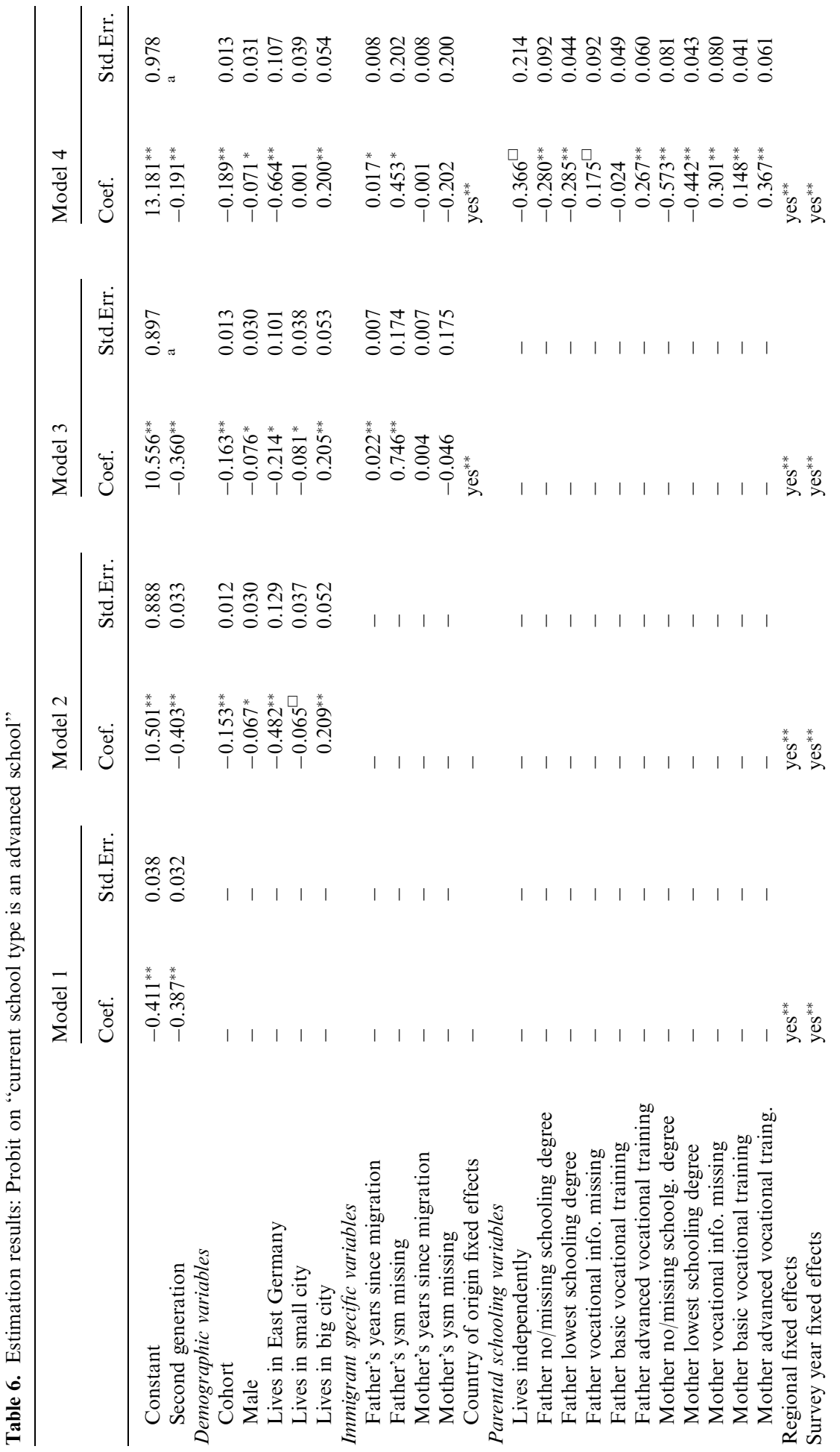




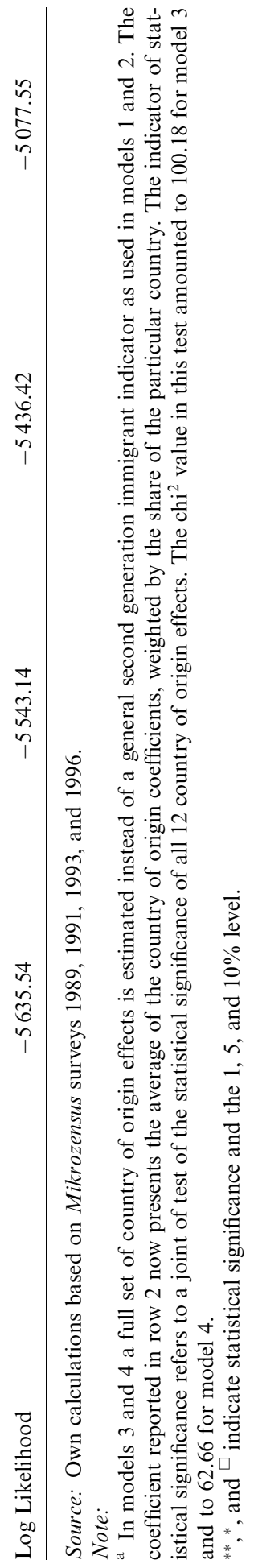


set of country of origin fixed effects. The assimilation indicators yield that a longer paternal stay in Germany increases childrens' probability of advanced school attendance. The country of origin fixed effects are jointly highly significant. Only second generation immigrants from Austria have higher chances of advanced school enrollment than natives. The lowest probabilities are measured for youth from Italy, Turkey, and former Yugoslavia. The average coefficient for second generation immigrants - weighted by population shares - amounts to -0.36 and predictions yield that ceteris paribus natives' probability of attending advanced school exceeds that of second generation immigrants' by 9.7 percentage points ( 25.2 vs. $15.3 \%$ ).

Finally, Model 4 adds detailed controls for parental schooling degrees and vocational training. The estimates confirm theoretical predictions: Higher parental education is significantly associated with a child's advanced school attendance. Interestingly, the coefficients for maternal schooling are almost twice as large as those for fathers. This translates ceteris paribus to a difference in school enrollment rates of 16 percentage points for children of mothers of a higher as opposed to no schooling degree. In contrast, fathers' schooling differences are predicted to yield only a 7.8 percentage point difference in advanced school enrollment probabilities. Even with these powerful predictors of educational attainment added to the model, the average second generation immigrant coefficient - again weighted by population shares - remains at -0.19 and the predicted enrollment advantage of natives over immigrants at 5 percentage points. Thus the explanatory variables explain only part of the difference in school attendance between natives and second generation immigrants. Potential additional factors are the language ability of immigrant youth, which we cannot consider because it is not measured in our data. Given the limited range of birth cohorts in this sample it is not useful to analyze cohort effects here. They will be investigated in Sect. 4.3 below. $^{17}$

To investigate whether covariate effects differ for natives and immigrants we estimated models interacting demographic and parental schooling indicators with second generation immigrant status. While these interactions yielded few individually significant coefficients, both the demographic and parental variable interactions were jointly highly significant. Thus demographics and parental human capital seem to affect natives and immigrants differently. ${ }^{18}$

\subsection{Analysis of completed degrees}

Next we investigate the difference in the highest educational degrees for natives and second generation immigrants. Table 4 presented evidence that on average immigrants' completed degrees are lower than natives'. When regressing completed degrees on an indicator of second generation immigrant status this yields a significant negative coefficient which persists when controlling for regional and survey year fixed effects as in Model 1 of Table 7.

In Model 2 we add demographic indicators. They yield highly significant coefficient estimates, confirming the findings from Sect. 4.1 that males and those living in smaller cities have lower educational degrees. In contrast to prior results we now find positive effects of younger birth cohorts and for living in Eastern Germany. One possible explanation for this divergence is 


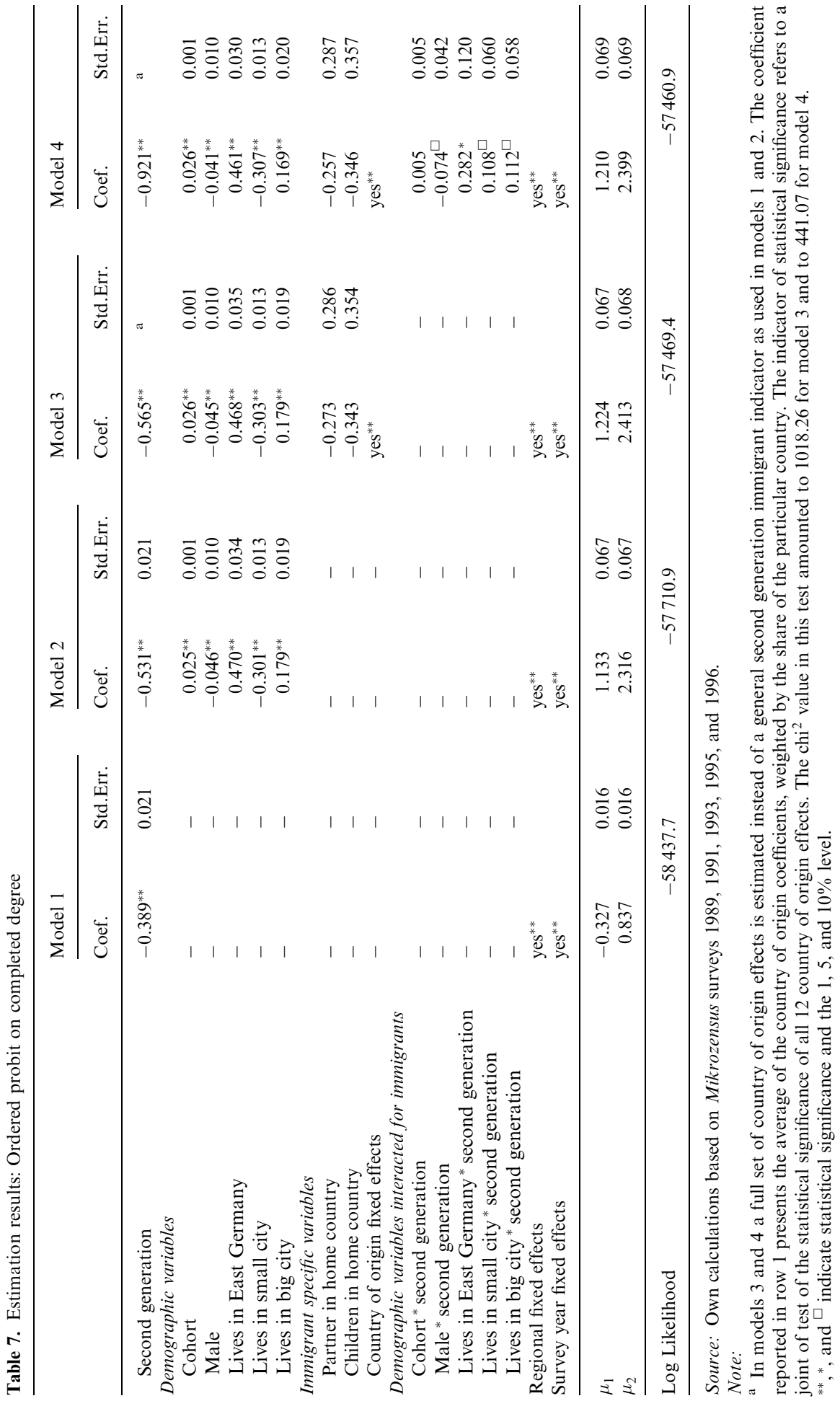


that we are now looking at a sample which was born earlier (1956-1974) than those observed attending school (1970-1980). Even though much explanatory power was added to the model by the demographic indicators, the second generation immigrant coefficient stays negative, highly statistically significant, and even increases in absolute magnitude.

The immigrant specific indicators country of origin and whether a partner or child lives in the home country were added in Model 3. The effects of the assimilation measures are insignificant, yet they weakly indicate that those with stronger ties to the home country and thus weaker assimilation on average have lower degrees in Germany, which is plausible. Note that these home country tie indicators are relevant only for a minute fraction of immigrants. The coefficients on the country of origin indicators are jointly highly significant. Immigrants from Austria, Great Britain, Poland, and France have the highest degrees. Nations with the least successful pupils in Germany seem to be Turkey at the bottom and then Italy, Spain, former Yugoslavia, Portugal, and Greece. The weighted average of the coefficient estimates is reported in Table 7 and similar to that in Model 2. This suggests that the overall educational gap is not due to the nationality composition in the second generation immigrant sample.

Model 4 in Table 7 adds interactions to the specification, as suggested in Eq. (2) above. Prior effects remain basically unchanged, and we find evidence for some differences in the correlation between demographic variables and educational outcomes across the samples.

\subsection{Cohort effects}

\subsubsection{The evidence}

The question addressed here is whether the divergence in schooling degree developments for the two groups (cf. Fig. 1) is statistically significant and robust. Table 8 reports the results of ordered probit estimations which consider separate cohort effects for natives and immigrants. The results in the row labeled "test" indicate that in all but the last specification the estimated cohort effects jointly differ significantly for the two samples.

The first model is an exact representation of Eq. (3) in Sect. 3.1. Since the signs of the overall second generation effect and the interaction effect differ, it is difficult to interpret the result by inspection and we present simulation results in Panel B of Table 8: The probability of each degree is calculated for natives and immigrants. The probability differences are presented for cohorts born in 1956 and 1972. The prediction based on model 1 yields that the difference in the probability of a low educational degree rose from about ten percentage points for the 1956 cohort to about 24 for those born 1972. Similarly, the probabilities of attaining an advanced degree differed by about six points for the 1956 and more than 18 percentage points for the 1972 cohort. ${ }^{19}$ This confirms the rising gap in educational attainment described in Fig. $1 .{ }^{20}$ This simple model was reestimated with quadratic, cubic, and categorically represented cohort effects which corroborated the findings (not presented). Thus the outcome seems to be robust to the parameterization of the cohort effect. 
However, the outcome might be sensitive to covariate controls or it may be driven by composition effects. To test this, we first added survey year and regional fixed effects to a model with quadratic cohort effects (Model 2 in Table 8). The quadratic cohort interactions are jointly significant and the predictions in Panel B are similar to those based on Model 1.

Demographic control variables are added in Model 3. Again the cohort interaction terms are jointly significant and the predictions in Panel B are nearly unchanged. Only in Model 4 when immigrant specific indicators and country of origin effects are added does the cohort effect of immigrants cease to differ significantly from that of natives. The twelve indicators describing immigrants' nationality are jointly as well as individually significant. Now the predicted gap in the probability of attaining an advanced degree for the two subsamples is much reduced.

The result that significant cohort differences are robust to the addition of explanatory variables, regional, and survey year fixed effects, but disappear once nationality indicators are considered, is independent of the parameterization of cohort effects. Therefore the country of origin composition of immigrants to Germany may be a determinant of the relative decline of second generation schooling attainment. Figure 2 depicts the distribution of second generation immigrants by nationalities across the cohorts in our sample. The nationality composition changed strongly, where the share of Turkish and Ex-Yugoslavian second generation immigrants increased from under ten and five percent in the late 1950 s to more than 50 and $20 \%$ in the 1974 cohort, respectively.

\subsubsection{Looking for an explanation}

The challenge now is to explain this finding. An important point to keep in mind is that parental background indicators are missing, which are not observed for this sample. One possible explanation of the results could be that unobserved characteristics ${ }^{21}$ are correlated with nationalities and that therefore the changing nationality composition somewhat spuriously affects the results. Unfortunately this hypothesis cannot be tested with the available data.

One may ask whether certain nationalities determine the relative decline in immigrants' educational attainment. ${ }^{22} \mathrm{We}$ pooled each nationality separately with natives to estimate linear cohort effects and their interactions. This yielded mixed results, as we find nationality groups with stronger and weaker improvements in school attainment than natives. Interestingly, the population share of immigrants from countries with declining relative attainments (i.e., Great Britain, Italy or Poland, cf. Fig. 2) fell between 1956 and 1974.

The explanation for this surprising fact is that the overall second generation cohort effect is not just a linear aggregation of all nationality-specific cohort effects relative to natives, but instead it is weighted by each nationality's changing share among immigrants: Turkish pupils improved over time compared to natives. Yet if their education is the lowest of all and their share in the total increased over time (cf. Fig. 2), average immigrant education may be observed to decline over time simply due to the reweighting of national groups. Table 9 shows that attainments differ strongly across 


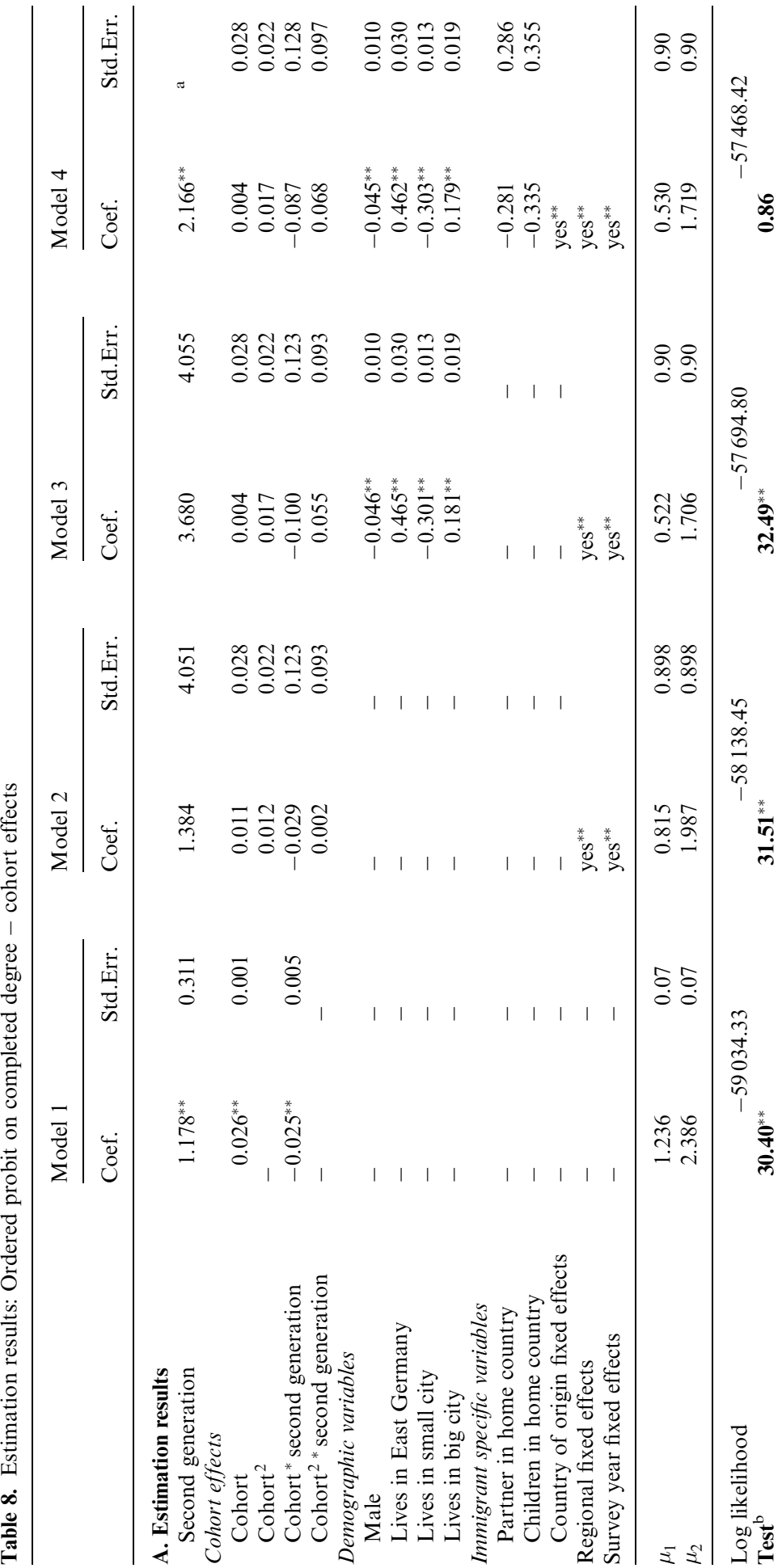




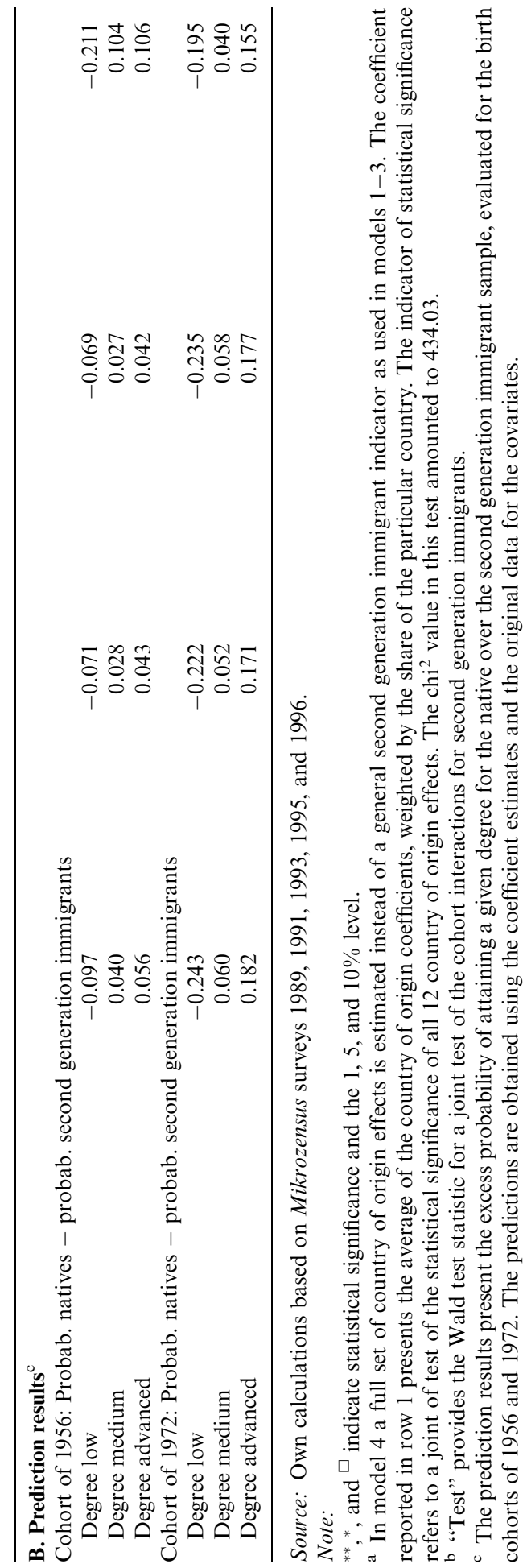




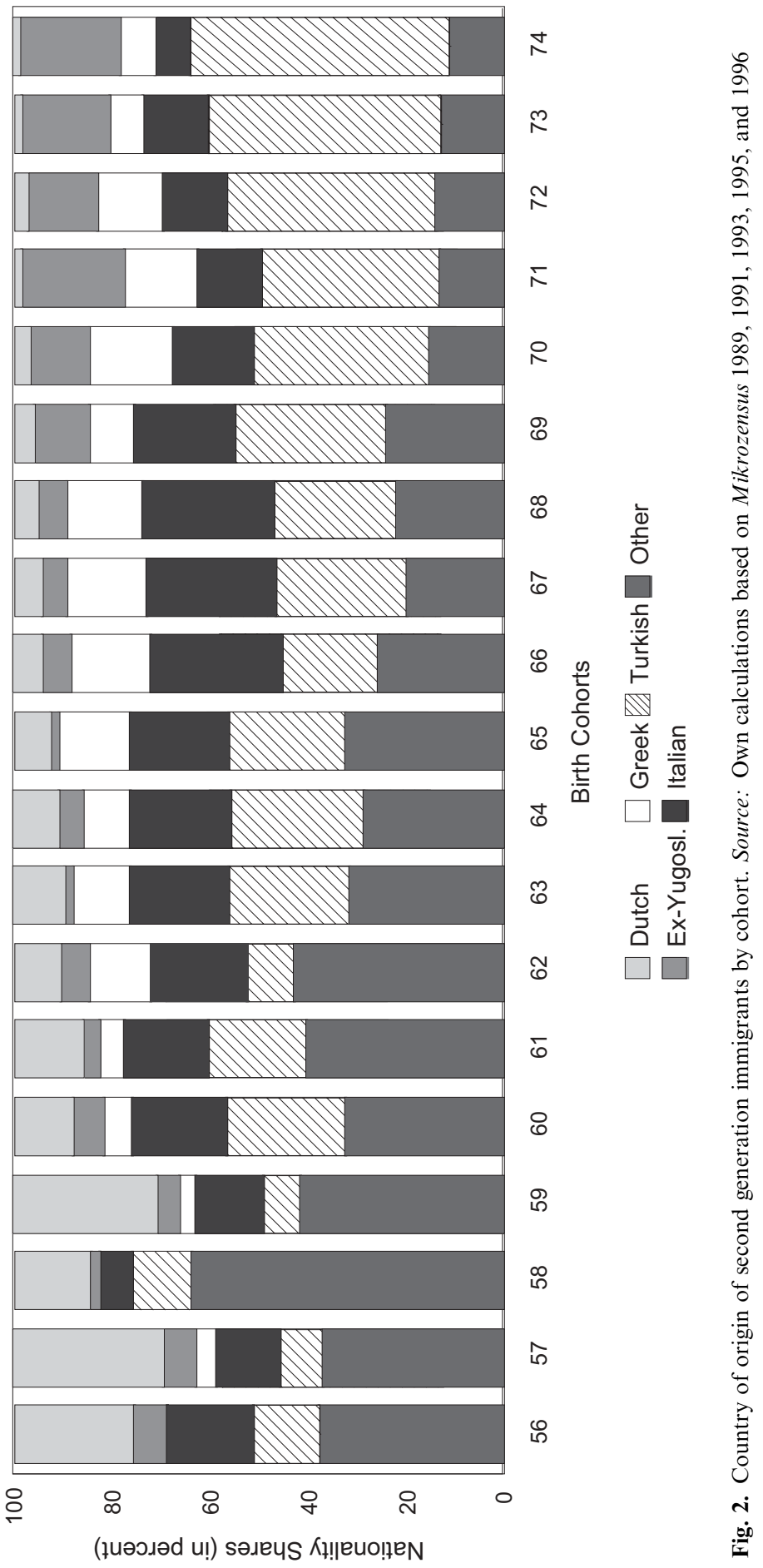




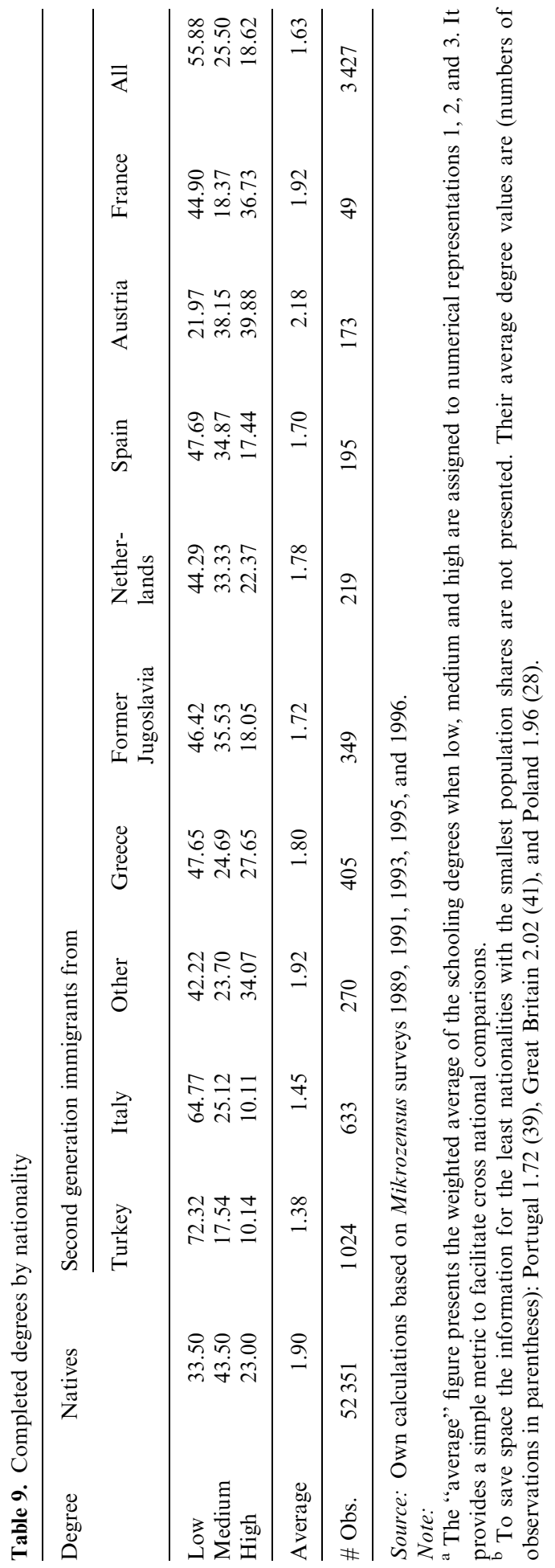


national groups with Turkey and Italy at the bottom. The estimations in Table 8 were repeated after dropping the Turks from the sample. The results (not presented) for the cohort effect among second generation immigrants were unchanged. This result remained even when Italians or former Yugoslavs were dropped as well. ${ }^{23}$ Thus, while the observed cohort effect is correlated with the country of origin composition of the sample, it does not seem to go back to the changing share of one specific country of origin.

\section{Conclusion}

This study is the first to investigate the educational attainment of German second generation immigrants using representative data of the Mikrozensus surveys. The educational success of the children of first generation immigrants is compared to that of natives, with an interest in developments over time.

A first analysis establishes that the educational attainment of immigrants, measured by current enrollment or highest completed degree, is significantly below that of natives. The educational gap between the two groups is statistically significant and robust to controls for available demographic measures, immigrant assimilation variables, parental human capital indicators, country of origin, regional, and yearly fixed effects. Therefore the factors, which based on theoretical models should determine educational outcomes, do not seem to be behind the second generation's overall educational disadvantage.

In a second step we investigate whether the achievement gap declined over time. This development would seem plausible for several reasons: German society and educational institutions over time may have learned to better serve the needs of the growing number of immigrants in the country. Also, if the integration occurred over time, growing assimilation advantages may have been passed from the first to the second generation of immigrants. For these reasons second generation immigrants' education should improve relative to natives'.

A description of completed degrees for subsequent birth cohorts does not confirm this hypothesized development. Multivariate analyses instead show that the overall educational gap between the two groups increases significantly over time. Several control variables in the regressions do not affect the estimated cohort effects. Only when the immigrants' country of origin is controlled for does the significant diverging trend between natives and second generation immigrants vanish. The exact mechanism behind this apparent composition effect could not be determined with the available data and remains to be investigated in future studies using richer data and in particular controlling for parental human capital.

Our main findings are that (even conditional) educational outcomes for second generation immigrants lag behind those of natives and that the overall gap in educational attainment between the two groups increases over time. While the attainment of natives has improved strongly over recent decades, second generation immigrants do not obtain higher degrees now than about two decades earlier. Overall, Hirschman's (2001) finding for the United States must thus be confirmed for the case of Germany as well, where second generation immigrants are falling behind educationally. 


\section{Endnotes}

${ }^{1}$ Existing studies typically focus on differences in the educational attainment of immigrants in general as compared to natives, without paying attention to first vs. second generation and cohort effects. Chiswick's (1988) analysis concentrates on testing a child investment model of family decision making, Borjas (1992) tests for the persistence of ethnicity effects across generations, and Leslie and Drinkwater (1999) evaluate the incentives to invest in education for natives and immigrants. German studies investigate the factors correlated with the level of schooling attained, see e.g., Gang and Zimmermann (2000), Haisken-DeNew et al. (1997) or Alba et al. (1994).

2 Based on the Mikrozensus data it can be shown that second generation immigrants made up cohort shares of more than $10 \%$ among children already in 1995 .

${ }^{3}$ See Riphahn (2000) for more detailed information.

${ }^{4}$ For simplicity the coefficient and disturbance term indicators are left identical across the four model descriptions. Formal correctness would require different labels in each equation.

5 An exception is the 1996 Mikrozensus where individuals with double citizenship were explicitly asked about their second nationality. However, only 107 individuals in our final sample provided information on their second nationality, a number too small to permit separate analyses. Also, to avoid nonrandom selection when analysing these cases, it would be important to distinguish between those individuals who hold a second citizenship "by accident" such as place of birth, as opposed to a conscious decision. These groups cannot be distinguished in the 1996 data.

${ }^{6}$ Germany does not consider itself an immigration country. Naturalization rules follow the ius sanguinis, which grants citizenship to ethnic Germans only. Thus until 1993 when the rules where changed, no foreigner could claim German citizenship. Instead, German citizenship could be granted by the administration to individuals who were married to a native, or who had spent at least 10 years in Germany and met a number of conditions (e.g., no criminal record, stable income, knowledge of German language). Since July 1, 1993 individuals have the right to be naturalized if (i) foreign citizens aged 16-23 give up their other citizenship (exceptions possible), lived in Germany for at least eight years, went to school in Germany for at least 6 years, and committed no crime. (ii) Also the right to become German is granted to those who have legally spent at least 15 years in Germany and meet a large number of conditions. Their spouses and children may then apply for citizenship but have no claim to it. In 2001 regulations became more generous, which however does not affect our data. The restrictive naturalization practice is reflected in aggregate naturalization rates which remain below $0.6 \%$ through 1993 and do not exceed 1.2\% of all foreigners in Germany through 1996. - Unfortunately the Federal Statistical Office does not provide naturalization figures by place of birth. Therefore we cannot cross-check for the magnitude of the potential problem.

${ }^{7}$ The share varies between $5.8 \%$ of the non German individuals in 1989, and a maximum of $18.2 \%$ in 1993 . The author is unaware of reasons for the variation in answering behavior, as e.g., the question was posed in an identical manner. A comparison of sample sizes across years suggests that the missing information is most likely to go back to first rather than second generation immigrants. While second generation immigrants simply had to check "born in Germany", first generation immigrants had to provide the immigration year. There are several reasons why such an answer may be difficult, among them problems of recall, of clear definition which of possibly several years of commuting between countries should be set as the immigration year, or the problem of possible illegal immigration. - For the first time the German Federal Statistical Office provided information on the overall share of second generation immigrants in all foreigners for December 31, 1996. The aggregate figure of $20.8 \%$ then compares very well to the $21.7 \%$ we find in the 1996 data, supporting the representative nature of our sample.

${ }^{8}$ Here it is important to point out that in principle pupils from any type of secondary school can enter the advanced school after grade 10, where the specific regulations vary across federal states.

9 The older the sample, the higher the fraction of missing values for the school attendance variable. For those aged 16 and 17 it is less than $1 \%$, at age 18 it increases to just under $5 \%$ and at age 19 it already exceeds $25 \%$. Therefore, even though some individuals may still attend advanced school at age 20 , they are not considered in the analysis. 
${ }^{10}$ If those who at age 19 have left the parental home differ in their (unobservable) characteristics from those still living at home, and if these differences are correlated with the dependent variable we would suffer a problem of endogenous sample selection when the independently living individuals were dropped from the sample. To consider them in the estimation we can either replace parental characteristics by the sample means or explicitly control for their missing nature. The latter is preferred here as it imposes weaker assumptions on the data. Section 4.1. reports estimation results obtained including and excluding those living independently.

${ }^{11}$ In a few cases the years since migration indicator is coded for a parent of a native child. In these situations possibly one parent is a first generation immigrant or the child is an offspring of ethnic Germans who migrated to Germany from Eastern Europe and were naturalized upon arrival.

12 Given the sampling rule of using only those aged 16 through 19 the average age for the two samples is merely identical at 17.52 for natives and 17.41 for second generation immigrants.

13 The regulations on degrees vary somewhat across federal states.

${ }^{14}$ This affected 5.8 and $5.5 \%$ of native and second generation immigrant observations, respectively.

15 This procedure might present a problem if natives and immigrants differ in the time they need to attain a given degree. However, first, the lack of a degree at age 22 is indicative of low educational attainment as well. Second in our data the probability to attain a (higher) degree does not increases noticably for either of the two subsamples if the age cutoff is raised from 22 to say 25 years.

16 The coefficient of -0.387 even exceeds that obtained without fixed effect controls $(-0.328)$.

${ }^{17}$ For a robustness test the estimations in Table 6 were repeated after dropping observations who no longer reside with their parents; clearly this represents a potentially endogenous selection. The estimated coefficients for the second generation indicator in Models 1-3 exceeded those presented in Table 6 in absolute magnitude. Only the estimate in Model 4 was smaller at -0.16 and no longer statistically significant $(p=0.177)$. If these results were not biased by endogenous selection this would suggests that (a) the gap in advanced school enrollment is robust to the treatment of those living independently and (b) that it can in part be explained by parental characteristics. However, it is plausible that the decision to move out from the parental home is correlated with parental characteristics. Thus the results obtained when using the selected sample are problematic.

${ }^{18}$ Estimation results available from the author upon request.

19 The predictions were obtained by applying all estimated coefficients, including the insignificant second generation main effect, to the data. The values of the cohort variables and the second generation indicators were modified to generate predictions for different groups and cohorts. These predictions are unlikely to be precise and merely illustrate the implications of the estimates.

${ }^{20}$ Separate estimations by sex confirmed these results with significantly different cohort effects by subsample for both sexes.

21 Alternative examples besides parental background are linguistic distance from German, or nationality specific changes in parental human capital over time. Also, supply side effects may play a role: If advanced schools were constructed in rural areas with low foreigner shares, this might explain natives' educational advancement. If certain immigrant groups are stronger represented in rural regions than others, this might be another unobservable transmission mechanism behind the observed changes.

22 When estimating cohort effects for each national group separately, we find significant positive cohort effects for Greece, the Netherlands, Austria, Turkey, Portugal and Spain.

${ }^{23}$ Even when dropping each of the nationality groups separately the results remained robust.

\section{References}

Alba RD, Handl J, Müller W (1994) Ethnische Ungleichheiten im deutschen Bildungssystem. Kölner Zeitschrift für Soziologie und Sozialpychologie 46(2):209-237

Becker GS (1981) A Treatise on the Family. Harvard University Press, Cambridge, Mass

Borjas GJ (1992) Ethnic Capital and Intergenerational Mobility. Quarterly Journal of Economics 107(1):123-150 
Borjas GJ (1994) Immigrant Skills and Ethnic Spillovers. Journal of Population Economics 7(2):99-118

Chiswick BR (1988) Differences in Education and Earnings across Racial and Ethnic Groups: Tastes, Discrimination, and Investments in Child Quality. Quarterly Journal of Economics 103(3):571-597

Emmerling D, Riede T (1997) 40 Jahre Mikrozensus. Wirtschaft und Statistik 3/97:160-174

Gang IN, Zimmermann KF (2000) Is Child Like Parent. Educational Attainment and Ethnic Origin. Journal of Human Resources 35(3):550-569

Haisken-DeNew JP, Büchel F, Wagner GG (1997) Assimilation and Other Determinants of School Attainment in Germany: Do Immigrant Children Perform as Well as Germans? Vierteljahreshefte zur Wirtschaftsforschung 66(1):169-179

Hirschman C (2001) The Educational Enrollment of Immigrant Youth: A Test of the SegmentedAssimilation Hypothesis. Demography 38(3):317-336

Leslie D, Drinkwater S (1999) Staying on in Full-Time Education: Reasons for Higher Participation Rates among Ethnic Minority Males and Females. Economica 66(261):63-77

Mayer J, Riphahn RT (2000) Fertility Assimilation of Immigrants: Evidence from Count Data Models, 2000. Journal of Population Economics 13(2):241-261

Riphahn RT (2002) Residential Location and Youth Unemployment: The Economic Geography of School-to-Work Transitions, forthcoming: Journal of Population Economics 15:115-135

STBA (Statistisches Bundesamt) (Various years) Statistical Yearbook for the Federal Republic of Germany, Metzler Poeschel, Wiesbaden 